\title{
MODIFIKASI PERMAINAN OLAHRAGA KRIKET UNTUK PEMULA
}

\author{
${ }^{1}$ Romi Mardela, ${ }^{1}$ Yendrizal, ${ }^{1}$ Alex Aldha Yudi \\ ${ }^{1}$ Jurusan Kepelatihan Fakultas Ilmu Keolahragaan Universitas Negeri Padang \\ Universitas Negeri Padang. Jl. Prof.Dr. Hamka Air Tawar, Padang, 25132, Indonesia. \\ Email: mardela@fik.unp.ac.id, yendrizal@fik.unp.ac.id, alexaldhayudi@fik.unp.ac.id
}

\begin{abstract}
Abstrak: Kriket merupakan salah satu cabang olahraga yang sedang berkembang di Indonesia oleh karena itu penyebarannya selalu digiatkan di berbagai kalangan masyarakat, salah satunya di perguruan tinggi. Pada tahun 2019 Kriket sudah mulai diperkenalkan pada kejuaraan resmi tingkat perguruan tinggi se Indonesia Pekan Olahraga Mahasiswa Nasional (POMNAS) yang diselenggarakan di Jakarta. Oleh karena itu maka cabang olahraga asal Inggris ini pun juga harus digiatkan pada perguruan tinggi di Sumatera Barat, khususnya Kota Padang. Dari kegiatan sosialisasi yang dilaksanakan disaat para mahasiswa tersebut telah mendapatkan materi tentang Kriket mereka menjadi antusias dan ingin mengenal lebih jauh lagi olahraga ini. Berdasarkan hal tersebut maka perlu untuk memodifikasi cabang olahraga ini agar bisa dimainkan pada berbagai tempat serta situasi pada di kampus masing-masing. Lebih jauh mereka berharap agar adanya latihan yang berkelanjutan untuk lebih memantapkan keterampilan mereka. Dengan artikel ini juga dapat menjadi panduan untuk melakukan latihan kriket.
\end{abstract}

Kata kunci: kriket, permainan, modifikasi, perguruan tinggi

\section{Cricket Games Modification for Beginner}

Abstract: Cricket is a sport just developing in Indonesia. On 2019 cricket has introduced to student at university level by official national games intervarsity in Indonesia and the next competition Universitas Negeri Padang, West Sumatera will be host for that bi-year sports championship. Writer has seen majority student from universities do not know yet about cricket, this problem has been solved by introduce cricket game for the beginner on university level and also modified cricket equipment and field so it can use in any form of condition in the university. There were several universities who invited to this ivent: Universitas Andalas, Universitas Islam Negeri Imam Bonjol, YPTK UPI, Universitas Muhammadiyah Sumatera Barat, Politeknik Negeri Padang. From this ivent the student hope that activities will be continue, so they can understand more about cricket sport also we facilitated them with equipment has already modified and can played in limited situation. Therefor from this event we hope they can start to develop cricket on their universities and make an organization to continuing their training in cricket.

Keywords: cricket, games, modification, university student 


\section{PENDAHULUAN}

Sebagai upaya membentuk manusia berkualitas salah satunya melalui pembinaan generasi muda dengan kegiatan olahraga. Olahraga dewasa ini tidak hanya dilakukan untuk mencari kebugaran atau kesegaran jasmani saja tetapi juga dilakukan untuk mencapai prestasi setinggi-tingginya sehingga dapat menaikan harkat dan martabat suatu daerah atau bangsa. Pada pasal 4 Bab II Undang-Undang RI No.3 tahun 2005 tentang Sistem Keolahragaan Nasional menyatakan:

"Keolahragaan nasional bertujuan memelihara dan meningkatkan kesehatan dan kebugaran, prestasi, kualitas manusia, menanamkan nilai moral dan akhlak mulia, sportivitas, disiplin, memepererat dan membina persatuan dan kesatuan bangsa, memeperkukuh pertahanan nasional, serta mengangkat harkat, martabat dan kehormatan bangsa".

Berdasarkan kutipan di atas, pembinaan olahraga bertujuan meningkatkan kualitas hidup masyarakat, sehingga secara konsisten perlu menempatkan olahraga sebagai integral dari pembangunan. Dari bebagai cabang olahraga yang telah berkembang luas di tengah-tengah masyarakat saat ini, Kriket merupakan salah satu cabang olahraga yang baru berkembang di Sumatera Barat. Pada tahun 2012 Kriket mulai dikenalkan di Sumatera Barat dengan ditandai dengan keputusan Persatuan Cricket Indonesia (PCI) dengan dibentuknya
Pengurus di Sumatera Barat yang diketuai Dr. Yendrizal. M,Pd dan seiring itu telah dilakasanakanya sosialisasi tentang olahraga Kriket di Sumatera Barat.

Dalam upaya untuk mengembangkan olahraga kriket dengan cepat tentu harus dilaksanakan sosialisasi dan pelatihan ke daerah kabupaten yang berada di Sumatera Barat. Seperti Padang Pariaman, Agam, Bukit Tinggi, Sijunjung, Sawahlunto, Pesisir Selatan, Darmasraya, Solok, dan Lima Puluh Kota, agar dapat menjadikan olahraga kriket menjadi olahraga yang sering dimainkan di lingkungan masyarakat baik di kota maupun di desa-desa. Dengan meningkatnya orang yang bermain kriket maka akan menumbuhkan dan meningkatkan jumlah atlet Kriket yang dapat berprestasi baik di Sumatera Barat, Indonesia, maupun Asia, bahkan Dunia. Dalam proses sosialisasi dan pelatihan olahraga cricket harus dilakukan secara tersusun, terencana, kontinu, dan berkesinambungan hingga semua kabupaten kota yang terdapat di Sumatera Barat.

Berdasarkan beberapa pendapat yang telah ada maka menurut pengamatan penulis salah satu faktor yang menyebabkan belum maksimalnya prestasi yang dicapai di Sumatera barat ini yaitu disebabkan oleh kurangnya masyarakat mengenal olaharaga Kriket, terutama di tingkat mahasiswa sehingga jumlah atlet prestasi masih terbatas dan belum memberikan persaingan di 
kalangan atlet Kriket di Sumatera Barat. Dengan adanya permasalahan tersebut maka dari itu perlu dilakukan sebuah pelatihan dan sosialisai di tingkat perguruan tinggi yang ada di Kota Padang yang bertujuan untuk mengenalkan, menumbuhkembangkan, dan menciptakan atlet yang berprestasi dalam cabang olahraga Kriket. Ada beberapa perguruan tinggi yang diharapkan untuk dapat ikut serta dalam kegiatan ini, diantaranya: Universitas Andalas, Universitas Islam Negeri Imam Bonjol, YPTK UPI, Universitas Muhammadiyah Sumatera Barat, Politeknik Negeri Padang. Melalui sosialisasi ini nantinya diharapkan akan banyak kompetisi kriket antara mahasiswa yang bisa digelar, sehingga prestasi akan dapat terus ditingkatkan serta bisa bersaing di tingkat nasional ataupun internasional.

Berdasarkan analisis situasi yang dilakukan bersama mitra, maka permasalahan yang harus ditangani bersama adalah:

1. Belum maksimalnya sosialisasi cabang olahraga Kriket ke berbagai tingkatan institusi pendidikan di Kota Padang.

2. Masih kurangnya minat mahasiswa perguruan tinggi di Kota Padang terhadap cabang olahraga Kriket.

3. Belum bisa dimainkan di perguruan tinggi karena keterbatasan peralatan dan tempat permainan.

\section{SOLUSI, DAN TARGET}

\section{A. SOLUSI}

Atas persoalan yang dihadapi mitra tersebut, maka diharapkan solusi untuk memecahkan masalah dalam kegiatan ini antara lain:

1. Memperkenalkan hakikat permainan olahraga Kriket secara menyeluruh dan rinci kepada mahasiswa di perguruan tinggi di Kota Padang.

2. Memperkenalkan olahraga Kriket secara sederhana dan bisa dimainkan dimana saja.

3. Menjelaskan dan mempraktikkan berbagai modifikasi permainan serta modifikasi sarana dan prasarana cabang olahraga Kriket.

\section{B. TARGET}

Target yang ingin dicapai melalui kegiatan pengabdian kepada masyarakat ini sebagai berikut:

1. Hakikat permainan Kriket dapat dipahami secara menyeluruh diantaranya peserta bisa mengaplikasikan ilmu pengetahuan Kriket itu sendiri.

2. Adanya produk model latihan Kriket yang inovatif, beserta petunjuk kegiatan secara efektif dan efisien serta bisa diterapkan di berbagai lokasi.

3. Terbentuknya kelompok/klub Kriket untuk meningkatkan kemampuan peserta mahasiswa di perguruan tinggi. 


\section{METODE PELAKSANAAN}

\section{A. Tempat dan Waktu}

Tempat pengabdian untuk kegiatan sosialisasi cabang olahraga kriket dilaksanakan di Ruang Sidang Fakultas Ilmu Keolahragaan, Universitas Negeri Padang. Dan untuk pelaksanaan kegiatan dilakukan di masing-masing kampus.

Waktu pengabdian dilaksanakan sejak proposal penelitian disetujui hingga bulan September 2019.

\section{B. Khalayak Sasaran}

Mahasiswa aktif di perguruan tinggi yang ada di Kota Padang diantaranya: Universitas Andalas, Universitas Islam Negeri Imam Bonjol, YPTK UPI, Universitas Muhammadiyah Sumatera Barat, Politeknik Negeri Padang.

\section{Metode Pengabdian}

Sesuai dengan tujuan yang ingin dicapai yang telah dikemukakan sebelumnya, maka metode kegiatan yang diterapkan adalah: ceramah, demontrasi, praktik dan diskusi dengan narasumber yang memahami tentang Kriket tersebut. Rancangan mekanisme pelaksanaan kegiatan $\mathrm{IbM}$ ini dilakukan dengan langkah-langkah yang terdiri dari tahapan, perencanaan, ceramah, demonstrasi, observasi dan evaluasi.
Kegiatan atau aktivitas dari masing-masing tahapan adalah sebagai berikut:

\section{Perencanaan}

Kegiatan-kegiatan yang dilakukan pada tahap perencanaan adalah:

\section{a. Pembentukan dan pembekalan}

\section{Bagi Mahasiswa}

Tim pelaksana diundang untuk mengadakan pertemuan persiapan pelaksanaan dengan melibatkan khalayak sasaran. Tim pelaksana kemudian memberikan pembekalan mengenai maksud, tujuan, rancangan mekanisme program pengabdian, dan beberapa hal teknis berkaitan dengan metode/teknik pelaksanaan

\section{b.Sosialisasi program pengabdian} pada pihak mitra (khalayak

\section{sasaran)}

Sosialisasi dilakukan dalam bentuk koordinasi dengan mengundang mahasiswa yang berkenaan dengan program yang akan dilaksanakan.

\section{c. Penyusunan program pelatihan}

Berdasarkan hasil identifikasi, hasil analisis permasalahan yang ada, hasil analisis kebutuhan, dan hasil analisis potensi yang ada, selanjutnya disusun program pelatihan.

\section{Tindakan}

Tindakan dalam kegiatan ini berupa implementasi Program. Kegiatankegiatan yang dilakukan dalam 
implementasi program adalah (a) pembentukan kelompok-kelompok para pelatih Kriket, (b) meningkatkan pengetahuan dan keterampilan para mahasiswa tentang model latihan Kriket yang diberikan, (c) mendemonstrasikan model latihan yang sudah dibuat, (d) pembinaan dan penerapan model latihan di lapangan.

\section{Observasi dan Evaluasi}

Observasi dilakukan terhadap proses latihan yang dilakukan oleh mahasiswa, selanjutnya diamati saat melakukan di lapangan. Beberapa hal yang diobservasi adalah kendala, kekurangan, dan kelemahan yang muncul dalam dalam proses latihan di lapangan. Evaluasi dilakukan terhadap kualitas latihan yang dilaksanakan berdasarkan tujuan latihan yang diharapkan. Produk yang dihasilkan dalam kegiatan pelatihan ini adalah model latihan dan meningkatnya kemampuan pemainnya dari segi fisik, teknik, taktik maupun mental dari pada sebelumnya.

Kegiatan Pengabdian Kepada Masyarakat (IbM) ini memerlukan beberapa jenis kepakaran atau keahlian. Jenis keahlian yang dibutuhkan yaitu: (1) Bidang Permainan Cabang Olahraga Kriket; (2) Bidang Strategi dan Taktik Latihan serta 3) Bidang analisis belajar gerak. Keterampilan yang dimiliki oleh tim pelaksana kegiatan Ipteks ini sangat relevan dengan kegiatan yang akan dilaksanakan. Sehingga dengan keahlian dan pengalaman tersebut akan dapat menunjang keberhasilan pelaksanaan kegiatan Ipteks bagi Masyarakat ini.

\section{PELAKSANAAN KEGIATAN}

Ada beberapa rangkaian Kegiatan Pengabdian Kepada Masyarakat Skim IPTEK Bagi Masyarakat (IbM) dengan judul "Sosialisasi Cabang Olahraga Kriket pada Mahasiswa pada Perguruan Tinggi di Kota Padang" yang telah dilaksanakan. Pada tanggal 31 Agustus-1 September 2019 bertempat di Ruang Sidang Fakultas Ilmu Keolahragaan, Universitas Negeri Padang. Kegiatan ini diikuti oleh perwakilan mahasiswa dari 12 perguruan tinggi di Kota Padang dan mahasiswa UNP.

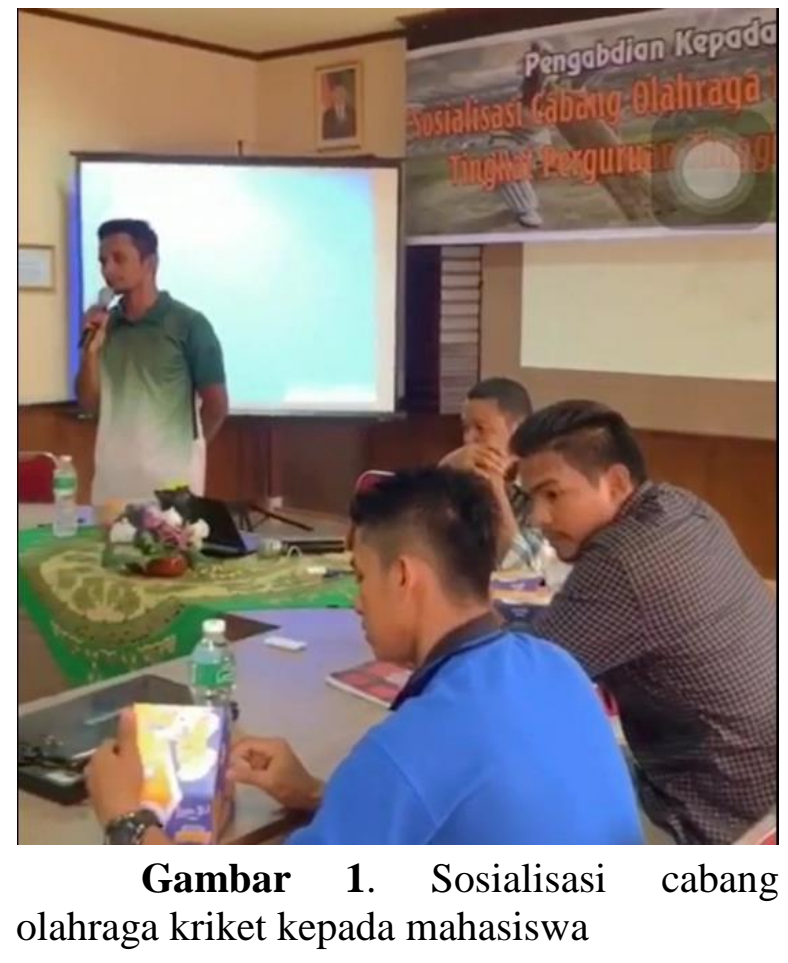


Jurnal Performa Volume 4 Nomor 2, Desember 2019 http://performa.ppj.unp.ac.id/index.php/kepel/index

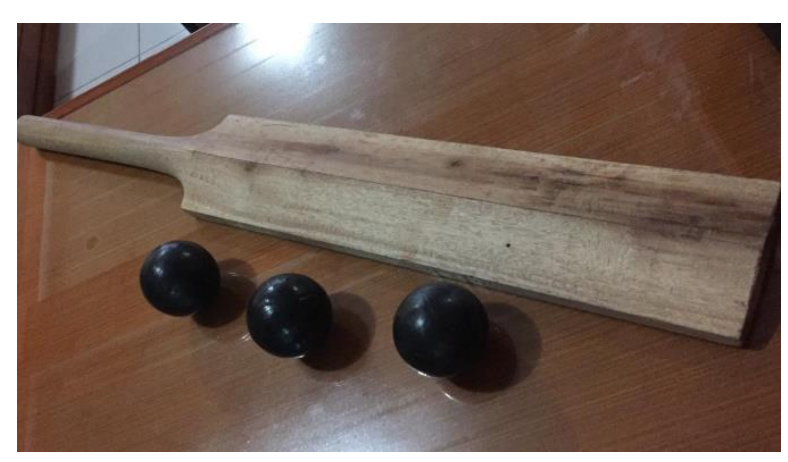

Gambar 2. Peralatan kriket yang dimodifikasi

Sosialisasi tersebut dilaksanakan selama dua hari. Terlihat disaat penjabaran teori belum banyak mahasiswa yang memahami dan mengetahui olahraga Kriket ini. Oleh karena itu perlu diberi penjelasan secara mendasar mulai dari teknik dasar, peraturan permainan, peralatan pertandingan dan perwasitan.

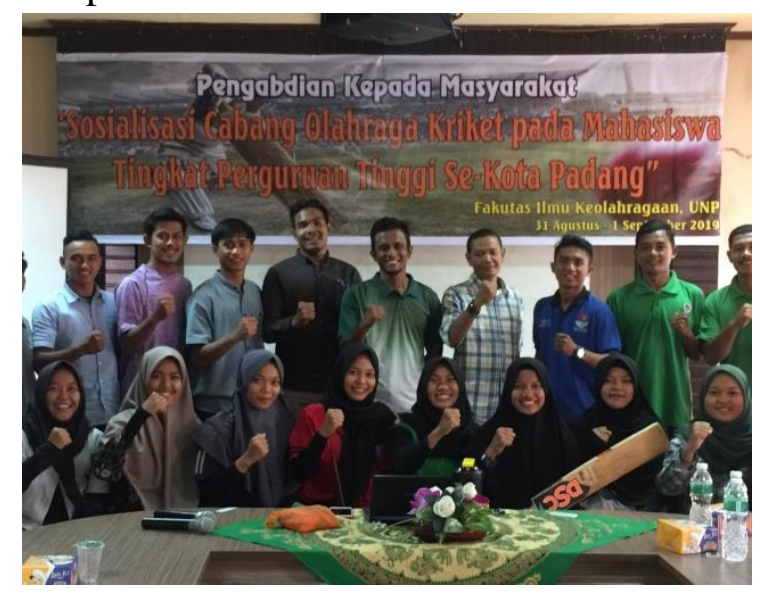

Gambar 3. Sosialisasi kegiatan kriket

Selanjutnya, setelah mereka mengetahui dan mengerti bagaimana permainan ini dapat dimodifikasi dan dilakukan dengan kondisi terbatas, sehingga para mahasiswa menjadi lebih tertarik dan merasa bahwa mereka bisa melakukan permainan cabang olahraga Kriket tersebut.
Hal ini terlihat dari antusias para mahasiswa di saat mencoba memainkan permainan yang mereka modifikasi sendiri.

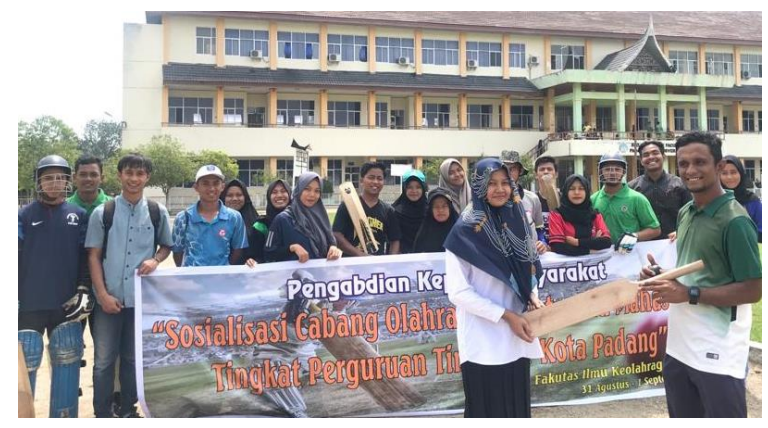

Gambar 4. Penyerahan bantuan alat kriket modifikasi

Selanjutnya pada sesi praktikum para mahasiswa diajarkan berbagai teknik dasar yang ada dalam permainan Kriket dimulai dari lempar tangkap untuk meningkatkan keterampilan fielding, keterampilan baling bola untuk posisi sebagai bowler, keterampilan memukul bola sebagai batsman, dan keterampilan sebagai wicket keeper.

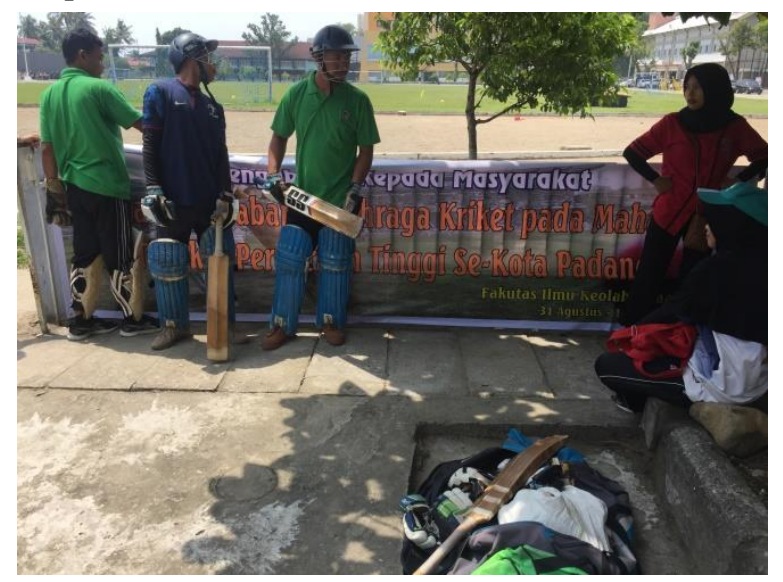

Gambar 5. Sesi praktikum kriket

Materi disampaikan dengan cara ceramah, demonstrasi dan diskusi. Kemudian jika ada kesalahan juga diberikan koreksi dan terapi untuk mengatasi kesalahan tersebut. 
Setelah penyampaian materi teknik dasar, para mahasiswa tersebut diminta untuk mempraktikan dalam bentuk permainan.

Lebih jauh dari hasil kegiatan ini, mereka berharap adanya pelatihan lebih lanjut terutama dalam hal pengembangan keterampilan bermain. Selain itu, mereka juga berharap agar adanya bimbingan awal sehingga nantinya mereka berharap dapat mengadakan pertandingan antar perguruan tinggi ataupun antar klub sebagai bentuk evaluasi serta menilai kemajuan yang telah mereka raih.

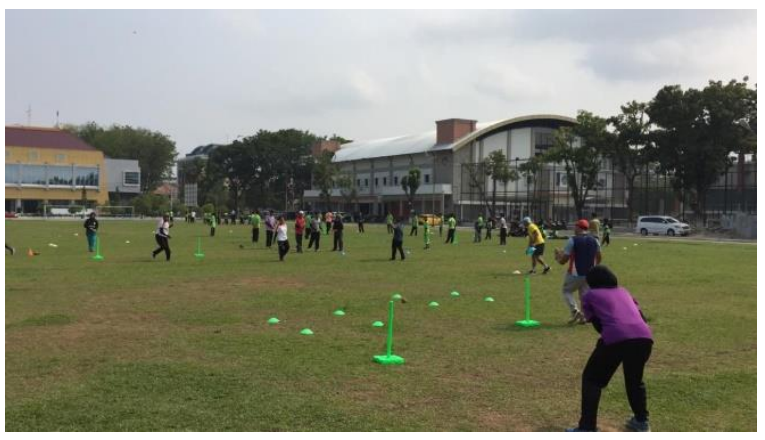

Gambar 6. Sesi praktikum latihan batting, bowling dan fielding

Setelah pelatihan tersebut, juga dianjurkan kepada para mahasiswa tersebut untuk membentuk unit kegiatan kriket di perguruan tinggi masing-masing, dengan dibantu memfasilitasi berupa peralatan yang dimodifikasi serta pendampingan untuk pembinaan nantinya. Akan tetapi setelah ditelusuri di beberapa perguruan tinggi, hanya ada dua universitas yang menyatakan berminat untuk melanjutkan ke pembentukan unit kegiatan kriket di kampus mereka yakni
Universitas Islam Negeri (UIN) Imam Bonjol dan Universitas Andalas meski demikian, mereka juga menyampaikan persoalan terkait dengan sarana dan prasaran di kampus mereka yang belum memadai dan untuk pengajuan ke pimpinan perguruan tinggi mereka akan upayakan.
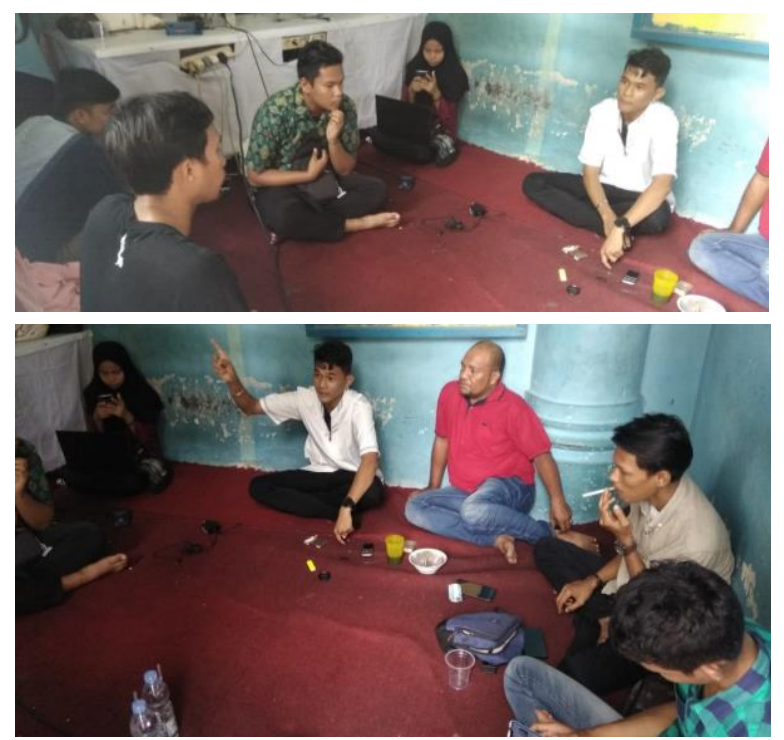

Gambar 7. Diskusi di UIN Imam Bonjol Padang tentang kelanjutan pelatihan dan pembentukan Unit Kegiatan Kriket di kampus mereka

\section{KESIMPULAN}

Dari pelaksanaan pengabdian kepada masyarakat dengan judul "Sosialisasi Cabang Olahraga Kriket pada Mahasiswa di Perguruan Tinggi di Kota Padang” yang telah dilaksanakan dapat disimpulkan bahwa kegiatan tersebut sangat diperlukan oleh semua lapisan masyarakat terutama bagi mahasiswa karena cabang olahraga kriket masih tergolong baru berkembang di Indonesia. Selain itu, kegiatan ini juga 
menjadi penting sebagai pengembangan keilmuan serta mempersiapkan mahasiswa di berbagai perguruan tinggi yang ada di Kota Padang khususnya untuk menghadapi kejuaraan kriket antar mahasiswa ataupun pada Pekan Olahraga antara Mahasiswa yang akan digelar pada tahun 2021 dan Sumatera

Barat menjadi tuan rumah.

\section{DAFTAR PUSTAKA}

Abdulhak, Ishak. 2007. Memposisikan Pendidikan Anak Dini Usia dalam Sistem Pendidikan Nasional". Buletin PADU. Jurnal Ilmiah Anak Usia Dini. Edisi 03, Desember 2002. Jakarta : Dir. PAUD, Dirjend. PLSP, Depdiknas.

Cricket Indonesia. 2015. Buku Panduan Cricket Indonesia. Persatuan Cricket Indonesia. Jakarta.

Daniel Dhakidae, ed. (2003). Profil Daerah: Kabupaten dan Kota Jilid 2. Penerbit Buku Kompas.

https://id.wikipedia.org/wiki/Kabupaten_Pesi sir_Selatan.Diakses pada tanggal 20 September 2015.

Malaysia Cricket Association. (2017) Sesions Plans, dan Games. MCA Level 1 Couching Course materi.

Peraturan pemerintah. 2000. Peraturan pemerintah republik Indonesia nomor 25 tahun 2000 tentang kewenangan pemerintan dan kewenangan provinsi sebagai daerah otonom.

Undang-undang. 1999. Undang-undang republic Indonesia nomor 22 tahun 1999 tentang pemerintah daerah.

\section{Acknowledge}

Dibiayai dengan Dana DIPA Universitas Negeri Padang, Nomor SP DIPA042.01.2.400929/2019, tanggal 5 Desember 2018 